\title{
Fibrin sealant injection through the drain with adjuvant compression as a treatment of groin lymphatic complications after vascular operation
}

\author{
Tadeusz Grochowiecki, Michał Macech, Tomasz Jakimowicz, Maciej Jędrasik, Sławomir Nazarewski \\ Department of General, Vascular and Transplant Surgery, Medical University of Warsaw, Poland
}

\begin{abstract}
Introduction: Groin lymphatic complications after femoral artery operations are rare, but if developed, they could be a source of severe complications that could be potentially fatal. The novel technique of combining compression and application of Tisseel sealant (Baxter AG, Vienna, Austria) to treat lymphatic fistulas in the groin region after common femoral artery exposure was evaluated.
\end{abstract}

Material and methods: Twelve groins from eleven patients with groin lymphatic complications were enrolled into the study. Patients had femoral artery exposure during one of the following procedures: endovascular aortic aneurysm repair, thrombendarterectomy or extra-anatomic by-pass. Postoperatively, average lymphatic drainage through the drain was $140 \pm 60$ (range 48-300) $\mathrm{mL}$ per day. Intervention was performed at a median of 12 (9-23) days after operation. The drain was cut off close to the skin, a thin double-channel catheter was introduced as deep as possible through the drain and sealant was injected into the wound. Simultaneously, the remaining part of the drain was removed, the orifice in the skin was sutured and a compression dressing was kept in place for 24 hours. The median patient observation period was 13 months (range 2.5-23) and surveillance of the groin was performed using ultrasonography.

Results: Early outcomes showed full technical success. None of the patients were readmitted due to lymphorrhea, infection or poor wound healing during follow-up. No lymphoceles were detected by ultrasonography.

Conclusion: Fibrin glue injection augmented by compression is an effective method for treating postoperative lymphatic fistulas and to prevent lymphorrhagia and lymphocele formation in the groin region after femoral artery exposure.

Key words: vascular surgery, lymphatic fistula, mini-invasive treatment, tissue sealant, femoral artery

Acta Angiol 2020; 26, 3: 85-89

\section{Article highlights}

Fibrin sealant injection through the groin drain with adjuvant compression after vascular operation stopped the leakage and prevented lymphorrhagia and lymphocele formation in median 13 months follow-up in all II patients.

\section{Introduction}

Groin lymphatic complications after vascular operations were estimated to be from I up to $1 \mathrm{I} .5 \%[\mathrm{I}, 2]$, and involved $92 \%$ of all wound complications after common femoral artery endarterectomies [2]. Groin lymphatic complications have several clinical scenarios.

Address for correspondence: Tomasz Jakimowicz, Department of General, Vascular and Transplant Surgery, Medical University of Warsaw, Banacha la St., 02-097 Warsaw, e-mail: tomj@wum.edu.pl 
At the beginning prolonged lymphatic outflow from the Redon drain can be noticed. After drain removal, a lymphocutaneous fistula through the channel of the drain or lymphorrhea from a disrupted or not completely healed wound can occur. After proper wound healing a lymphocele can be formed as a cystic collection of lymphatic fluid from open lymphatic vessels that form a pocket in the soft tissue. All of the above complications disturb wound healing and could lead to severe infections followed by septic bleeding and death. Prolongation of the postoperative stay raises the costs of treatment [3-5]. For each kind of groin lymphatic complication, many therapies have been described, though none have emerged as the best management. Thus, the application of preventive approaches seems to be the most appropriate solution. At first incision and careful ligation of the dissected tissue is extremely important $[3,6]$. In a randomized study, Swinnen et al. [7] showed a significant decrease in lymphatic leaks after femoral artery surgery using a transverse (12.7\%) rather than vertical incision (27.9\%). Giovannacci et al. [8] also presented in a prospective randomized study, a significant reduction of $19 \%$ to $10 \%$ in lymphatic complications after the prophylactic application of fibrin glue to the inguinal wound before closure. Proper management with a groin drain can prevent subsequent uncontrolled lymphorrhea or lymphocele formations.

\section{Objective}

The goal of this study is to determine the efficacy of a fibrin sealant injection through a drain augmented by compression as a treatment of prolonged lymphatic discharge from a Redon drain to avoid lymphorrhea or lymphocele formation after common femoral artery exposure.

\section{Material and methods}

Twelve groins with prolonged lymphatic drainage from a Redon drain after femoral artery exposure in eleven patients were assessed. Subjects were enrolled between November 2016 and March 2018. The median age was 71 years (range $58-85$ ). In the presented group, six patients $(50 \%)$ had undergone endovascular aortic aneurysm repairs, two $(16 \%)$ thrombendarterectomies of the common femoral artery and three had extra-anatomic by-pass grafts: aorto-bifemoral, subclavian-bifemoral and femorofemoral crossover by-pass graft.

The standardized surgical technique for wound closure consisted of accurate hemostasis, installation of a Redon drain near the femoral artery and sutures to the subcutaneous tissue and skin. The drain was conducted to the skins surface through a separate incision.
Prolonged lymphatic outflow from the Redon tube was defined as a lymphatic drainage of at least $30 \mathrm{~mL}$ per day through a 14 or 16 French drain with a negative pressure for more than 7 days. The amount and character of the exudate was assessed every day. Median time from the primary vascular operation to the procedure was 12 (9 to 23) days. For all patients, informed consent was taken before the procedure. This study was approved by the institutional review board. Characteristics of the patients and drainage are presented in Table I.

The procedures were performed in an operation theatre [9]. No bacterial culture samples were taken prior the procedure due to a lack of clinical signs of surgical site infection - wounds healing process was uneventful. The procedure started by cutting off the drain $5 \mathrm{~cm}$ above the skin. Through the drain, a thin dual-channel catheter was introduced to the end. The catheter was connected to two syringes with a ready to use Tisseel sealant (Baxter AG, Vienna, Austria), prepared according to the prescribing information [10]. Then, the tissue glue was injected alongside the simultaneous removal of the remaining part of the drain tip of the drain was sent for bacterial culture. Glue was injected as long as it came out through the drain's hole. No more than $10 \mathrm{~mL}$ of the glue was necessary. Subsequently, a single skin stitch was placed to close the area of drain removal and a compression dressing was applied with immobilization of the patient introduced for 24 hours.

Patient surveillance lasted for nearly two and a half months to over 22 months. Ultrasound examinations of the groin, performed I-3 months after glue injection, were undertaken for each patient to exclude lymphocele.

\section{Results}

There was $100 \%$ technical success. All lymphatic fistulas stopped immediately after the procedure. Seven (63\%) patients were discharged in the 2 days after the procedure, and the rest of the study group was discharged at 4 to 6 days. None of the patients developed lymphorrhea during the median 13 month follow-up. There were no readmissions due to poor healing of the wound, skin necrosis or surgical site infection. No signs of lymphocele were observed under ultrasound control during follow-up. Outcomes, follow-up and patient survival are presented in Table 2.

\section{Discussion}

Prolonged lymphatic discharged from a Redon drain after femoral artery exploration is a nuisance for both 
Table I. Demography, risk factors, types of operation, duration and amount of drainage

\begin{tabular}{|c|c|c|c|c|c|c|c|}
\hline No. & Sex & Age & $\begin{array}{l}\text { Important } \\
\text { comorbidities }\end{array}$ & $\begin{array}{c}\text { Type } \\
\text { of operation }\end{array}$ & $\begin{array}{c}\text { Type } \\
\text { of incision }\end{array}$ & $\begin{array}{l}\text { Postoperative } \\
\text { duration of } \\
\text { lymph drainage } \\
\text { (days) }\end{array}$ & $\begin{array}{l}\text { Drainage } \\
\text { Mean (max-min) } \\
\pm \mathrm{sd}(\mathrm{ml})\end{array}$ \\
\hline 1 & $\mathrm{~F}$ & 58 & No & EVAR raaa & Transverse & 14 & $300(40,500) \pm|5|$ \\
\hline 2 & $M$ & 58 & Tobacco abuse & $\begin{array}{l}\text { Aortobifemoral } \\
\text { by-pass }\end{array}$ & Longitudinal & 11 & $91(50-140) \pm 26$ \\
\hline 3 & $\mathrm{~F}$ & 83 & Diabetes mellitus & $\begin{array}{l}\text { TEA femoral } \\
\text { artery }\end{array}$ & Longitudinal & 9 & $151(60-200) \pm 49$ \\
\hline 4 & $M$ & 84 & $\begin{array}{l}\text { Anticoagulant } \\
\text { therapy, diabetes } \\
\text { mellitus, heart } \\
\text { failure }\end{array}$ & EVAR AAA & Transverse & 17 & $122(30-270) \pm 68$ \\
\hline 5 & $M$ & 71 & Diabetes mellitus & $\begin{array}{c}\text { Aortobifemoral } \\
\text { by-pass }\end{array}$ & Longitudinal & 13 & $130(75-200) \pm 53$ \\
\hline 6 & $M$ & 71 & Tobacco abuse & $\begin{array}{l}\text { Suprapubic } \\
\text { by-pass }\end{array}$ & Longitudinal & 12 & $136(90-200) \pm 31$ \\
\hline 7 & $\mathrm{~F}$ & 77 & Diabetes mellitus & EVAR AAA & Transverse & 23 & $172(30-340) \pm 73$ \\
\hline 8 & $M$ & 64 & No & Mbevar TAAA & Transverse & 14 & $157(40-800) \pm 191$ \\
\hline 9 & $M$ & 85 & $\begin{array}{c}\text { COPD, tobacco } \\
\text { abuse }\end{array}$ & $\begin{array}{c}\text { TEA femoral } \\
\text { artery }\end{array}$ & Longitudinal & 8 & $48(20-90) \pm 23$ \\
\hline $\begin{array}{l}10-\text { left } \\
\text { groin }\end{array}$ & $M$ & 68 & \multirow{2}{*}{$\begin{array}{c}\text { Obesity, diabetes } \\
\text { mellitus, tobacco } \\
\text { abuse }\end{array}$} & \multirow{2}{*}{ Fevar jaaa } & Transverse & \multirow{2}{*}{13} & $149(40-250) \pm 65$ \\
\hline $\begin{array}{l}\text { II - right } \\
\text { groin }\end{array}$ & & & & & Transverse & & $140(40-350) \pm 100$ \\
\hline 12 & $M$ & 68 & No & EVAR AAA & Transverse & 10 & $105(50-150) \pm 38$ \\
\hline
\end{tabular}

EVAR: endovascular aneurysm repair; rAAA: ruptured abdominal aortic aneurysm; TEA: thrombendarterectomy of femoral artery; mbEVAR: multibranched endovascular aneurysm repair; TAAA: thoracoabdominal aneurysm repair; fEVAR: fenestrated endovascular aneurysm repair; jAAA: juxtarenal abdominal aneurysm repair; COPD: chronic obstructive pulmonary disease

Table 2. Patient follow-up

\begin{tabular}{|l|c|c|c|c|}
\hline No. & Follow-up (months) & Appearance of lymphorea or lymphocele & Alive & Reason for death \\
\hline 1 & 21 & No & Yes & \\
\hline 2 & 23 & No & Yes & \\
\hline 3 & 23 & No & No & Circulatory insufficiency* \\
\hline 4 & 3 & No & Yes & \\
\hline 5 & 13 & No & Yes & \\
\hline 6 & 15 & No & Yes & \\
\hline 7 & 18 & No & Yes & \\
\hline 8 & 3 & No & Yes & \\
\hline 9 & 2,5 & No & No & \\
\hline $10-$ left groin & 4 & No & & \\
\hline $11-$ right groin & & No & Yes & \\
\hline 12 & 6 & No & & MOF \\
\hline
\end{tabular}

*Death not linked to the sealing procedure or prior vascular operation; MOF: multiorgan failure 
the surgeon and the patient. While there is currently no precise definition for this complication, two factors have to be taken into account according to the literature: duration of drainage and amount of lymph discharge in $\mathrm{mL}$ per day. Dietl et al. and Toepel defined this pathology as a secretion of a minimum of $50 \mathrm{~mL}$ per day for more than 4 and 7 days after surgery, respectively [2, II]. In this study, according to Giovannacci et al. [8], leakage above $30 \mathrm{~mL}$ per day was established as incorrect. The median duration of leakage was 12 days, in opposite of the 3 days due in Giovannacci's definition [8]. In our series, the waiting time from the operation to drain removal with simultaneous sealing was longer, because spontaneous disappearance of the leakage was assumed day by day. Prolongation of drain removal can be justified by Van den Brande et al. [12] findings. They showed an $82.6 \%$ healing rate for postoperative lymphocutaneous fistulas within 3 weeks of drainage; however, a $4 \%$ infection rate was observed. Shermak [13] showed that the mean time to identification of groin lymphatic complications after vascular surgery was 14 days. Thus, determining the right time of drain removal is crucial to preventing lymphorrhagia and lymphocele. Removing the drain too early can cause leakage through the wound and as a consequence, further measurements of the lymphatic liquid would not be possible. Moreover, it would necessitate the replacement of sodden compresses several times a day and increase the threat of infection. In this situation, application of vacuum-assisted closure therapy has been shown to be an appropriate management technique [14]. The method of successful injection of fibrinogen and thrombin through the wound drain with simultaneous pressure for $\mathbf{4 8}$ hours was introduced, with success, to treat lymphatic fistulas after the resection of lymphangiomatous tumor of the abdominal wall by Giberson [15]. Moreover fibrin glue is effective in the prevention of lymph leakage when used during wound closure and to treat lymphoceles of the groin $[16,17]$. In this study, Tisseel a two-component fibrin sealant made from pooled human plasma was used. The first component was thrombin with calcium chloride, and the second consisted of fibrinogen and aprotinin. Thrombin is a highly specific protease that transforms fibrinogen into fibrin. Aprotinin is a protease inhibitor that increases the resistance of the fibrin sealant clot to degradation in a fibrinolytic environment. When the two components are combined, the final stage of the blood coagulation cascade is mimicked and thus, hemostasis and sealing or gluing of tissues are achieved. Tisseel is also effective in heparinized patients and in patients medicated with anti-platelet drugs [10].

It has been shown that prothrombin, factor $\mathrm{V}$, fibrinogen and plasminogen are present in lymph in a concentration of about $20-60 \%$ of the plasma levels. Lymph also contains only small quantities of the various inhibitors of the fibrinolytic system [18, 19]. Thus, lymph clotting is slower, but its fibrinolytic activity is considerably higher than that of the blood [20, 2I]. Although the lymph does not contain any thrombocytes, thromboplastin formation is sufficient for clot formation [22, 23]. Thus, it can be assumed that the mechanism of action of the sealant is to simultaneously increase coagulation and decrease the fibrinolytic lymph properties. In this study, the action of the sealant was combined with a pressure dressing for 24 hours. Compression decreases lymphatic flow, which may wash out the fibrin glue before it can adhere to a tissue surface. In this study, a skin stitch was placed to close the hole after drain withdrawal to stop the glue leaking out. Thus, the necessity and duration of the pressure dressing application should be evaluated.

In conclusion, in this study, for the first time, drain removal with subsequent sealing to treat prolonged lymphatic drainage from a Redon tube was described. This method appears to be noninvasive, simple and highly effective. Moreover, it prevented the development of lymphorrhea and lymphoceles over the one year period of observation. There were no incidences of infection as a result of the drain removal with subsequent sealing and this was performed in an operating theater under antibiotic prophylaxis.

This study has several limitations due to its nonrandomized character and small cohort. The following issues are open for further research: What is the best point in time to remove the drain with sealing and whether it would be safe to carry out such procedures in an outpatient clinic. To solve those problems further randomized studies should be undertaken.

\section{Conflict of interest}

None.

\section{References:}

I. Tyndall S, Shepard A, Wilczewski J, et al. Groin lymphatic complications after arterial reconstruction. Journal of Vascular Surgery. 1994; 19(5): 858-864, doi: 10.1016/50741-52।4(94)700। I-7.

2. Uhl C, Götzke H, Woronowicz S, et al. Treatment of lymphatic complications after common femoral artery endarterectomy. Ann Vasc Surg. 2020; 62: 382-386, doi: 10.1016/j. avsg.2019.06.01 I, indexed in Pubmed: 31449944.

3. Ploeg AJ, Lardenoye JWP, Peeters MPF, et al. Wound complications at the groin after peripheral arterial surgery sparing the lymphatic tissue: a double-blind randomized clinical trial. Am J Surg. 2009; 197(6): 747-75I, doi: 10.1016/j.amjsurg.2008.04.014, indexed in Pubmed: 18929355.

4. Teixeira G, Loureiro L, Machado R, et al. Groin wound infection in vascular surgery. A one year institutional incidence. 
Angiologia e Cirurgia Vascular. 20I5; I (I): 3-10, doi: 10.1016/j. ancv.2014.12.001.

5. Obara A, Dziekiewicz MA, Maruszynski M, et al. Lymphatic complications after vascular interventions. Wideochir Inne Tech Maloinwazyjne. 20I4; 9(3): 420-426, doi: 10.5II4/ wiitm.2014.4302I, indexed in Pubmed: 25337I68.

6. Caiati JM, Kaplan D, Gitlitz D, et al. The value of the oblique groin incision for femoral artery access during endovascular procedures. Ann Vasc Surg. 2000; 14(3): 248-253, doi: I0. I007/ sl00169910042, indexed in Pubmed: 10796956.

7. Swinnen J, Chao A, Tiwari A, et al. Vertical or transverse incisions for access to the femoral artery: a randomized control study. Ann Vasc Surg. 2010; 24(3): 336-341, doi: 10.1016/j. avsg.2009.07.020, indexed in Pubmed: 19962270.

8. Giovannacci L, Eugster Th, Stierli P, et al. Does fibrin glue reduce complications after femoral artery surgery? A randomised trial. Eur J Vasc Endovasc Surg. 2002; 24(3): 196-201, doi: 10.1053/ ejvs.2002.1667, indexed in Pubmed: 12217279.

9. https://youtu.be/daPHIkGZCfE.

10. https://www fda gov/media.

II. Dietl B, Pfister K, Aufschläger C, et al. [Radiotherapy of inguinal lymphorrhea after vascular surgery. A retrospective analysis]. Strahlenther Onkol. 2005; I8I (6): 396-400, doi: I0.1007/ s00066-005-1364-0, indexed in Pubmed: 15925983.

12. Van den Brande P, von Kemp K, Aerden D, et al. Treatment of lymphocutaneous fistulas after vascular procedures of the lower limb: accurate wound reclosure and 3 weeks of consistent and continuing drainage. Ann Vasc Surg. 2012; 26(6): 833-838, doi: 10.1016/j.avsg.2012.02.009, indexed in Pubmed: 22727062.

13. Shermak MA, Yee K, Wong L, et al. Surgical management of groin lymphatic complications after arterial bypass surgery. Plast Reconstr Surg. 2005; I I5(7): 1954-1962, doi: I0.1097/0I . prs.0000165069.15384.e5, indexed in Pubmed: 15923843.

14. Hamed O, Muck PE, Smith JM, et al. Use of vacuum-assisted closure (VAC) therapy in treating lymphatic complications after vascular procedures: new approach for lymphoceles. J Vasc Surg. 2008; 48(6): 1520-1523, doi: 10.1016/j.jvs.2008.07.059, indexed in Pubmed: 19118737.

15. Giberson W, McCarthy P, Kaufman B. Fibrin glue for the treatment of persistent lymphatic drainage. Journal of Pediatric Surgery. 1988; 23(I2): II88-I I89, doi: 10.1016/s00223468(88)80340-3.

16. Boaventura P, Sobreira M, Yoshida W, et al. Tratamento de linfocele inguinal pós-operatória com injeção de cola de fibrina: relato de caso. Jornal Vascular Brasileiro. 2007; 6(2): 190-192, doi: 10.1590/s |677-54492007000200017.

17. Silas AM, Forauer AR, Perrich KD, et al. Sclerosis of postoperative lymphoceles: avoidance of prolonged catheter drainage with use of a fibrin sealant. J Vasc Interv Radiol. 2006; I7(I I Pt I): 179|-1795, doi: 10.1097/0I.RVI.0000242167.99055.3I, indexed in Pubmed: 17142709.

18. Brinkhous KM, Walker SA. Prothrombin and fibrinogen in lymph. Am J Physiology. 194I; I32(3): 666-669, doi: 10.1152/ ajplegacy. 194I.132.3.666.

19. Blomstrand R, Nilsson IM, Dahlbäck O. Coagulation studies on human thoracic duct lymph. Scand J Clin Lab Invest. 1963; 15: 248-254, doi: 10.3109/00365516309079740, indexed in Pubmed: $1397 \mid 764$.

20. Mayanskii DN, Minnibaev MM. A comparative study of the clotting power of the blood and lymph. Bulletin of Experimental Biology and Medicine. 1966; 62(4): 1097-1098, doi: 10.1007/bf00795446.

21. Kuznik BI, Levin YM. Lymph coagulation and fibrinolytic activity. Gematologiya i transfuziologiya. 2012; 57: 42-47.

22. Fantl P, Nelson JF. Coagulation in lymph. J Physiol. 1953; I22(I): 33-37, doi: 10.1113/jphysiol.1953.sp004976, indexed in Pubmed: 13109738.

23. Müller N, Danckworth HP, Müller N, et al. [Coagulation properties of the extravascular fluid. I. Coagulation factors in thoracic-duct lymph]. Z Lymphol. 1980; 4(I): II-17, indexed in Pubmed: 7456635. 